\title{
EL ANTI-NEOLIBERALISMO COMO ESTRATEGIA DISCURSIVA DE CONSTRUCCIÓN POLÍTICA: LOS DISCURSOS DEL GOBIERNO ARGENTINO EN EL CANJE 2003-2005
}

\section{O ANTI-LIBERALISMO COMO ESTRATÉGIA DISCURSIVA DE CONSTRUCÃO POLÍTICA: OS DISCURSOS DO GOVERNO ARGENTINO NA NEGOCIAÇÃO 2003-2005}

\section{ANTI-LIBERALISM AS A DISCURSIVE STRATEGY FOR POLITICAL CONSTRUCTION: THE DISCOURSE EMPLOYED BY THE ARGENTINE GOVERNMENT IN NEGOTIATIONS FROM 2003-2005 \\ L'ANTILIBÉRALISME EN TANT QUE STRATÉGIE DISCURSIVE DE CONSTRUCTION POLITIQUE : LES DISCOURS DU GOUVERNEMENT ARGENTIN DANS LES NEGOCIATIONS DE 2003-2005}

反自由主义作为政治构建的话语战略: 2003-2005年外债谈判期间阿根廷政府的政治话语

DOI: 10.5533/1984-2503-20135304

Alejandro Gabriel Manzo ${ }^{1}$

\section{RESUMEN}

Este artículo presenta e interpreta los discursos que, durante el proceso de canje de la deuda externa 2003-2005, activaron los representantes del gobierno argentino a la hora de invertir la lógica argumentativa desplegada por el Fondo Monetario International (FMI) para justificar la profundización del neoliberalismo en el país luego de la "crisis del 2001". A tal fin, utiliza un corpus de datos compuesto por una muestra pertinente de 59 artículos del diario Clarín que se analizan a partir de herramientas metodológicas propias del análisis de discurso. Se parte de presuponer que dicha tarea permitirá reflexionar, en un mayor grado de abstracción, sobre las características de un emergente discurso "antineoliberal" como eje legitimador de la agenda política del oficialismo en Argentina.

Palabras clave: (Anti-)neoliberalismo, FMI, Discurso Político, Deuda Externa, Crisis Financieras.

\footnotetext{
${ }^{1}$ Doctor en Derecho y Ciencias Sociales y Magister en Sociología de la Universidad de Córdoba (UNC), Argentina. Magister del Instituto Internacional de Sociología Jurídica (IISJ) Oñati, España.

E-mail: alemanzzo@hotmail.com
} 


\section{RESUMO}

Este artigo apresenta e interpreta os discursos que, durante o processo de negociação da dívida externa 2003-2005, os representantes do governo argentino acionaram no momento de inverter a lógica argumentativa empregada pelo Fundo Monetário Internacional (FMI) para justificar o fortalecimento do neoliberalismo no país após a "crise de 2001". Utiliza um corpus de dados composto por uma mostra pertinente de 59 artigos do jornal Clarín analisados a partir de ferramentas metodológicas de análise de discurso. Pressupõe-se que esta tarefa permitirá refletir, com maior grau de abstração, acerca das características de um emergente discurso "anti-neoliberal" como eixo legitimador da agenda política do oficialismo na Argentina.

Palavras-chave: (Anti-)neoliberalismo, FMI, Discurso Político, Dívida Externa, Crise Financeira.

\section{ABSTRACT}

This article outlines and interprets the discourse which representatives of the Argentine government instigated during the process of negotiating external debt from 2003 to 2005 in inverting the argumentative logic employed by the International Monetary Fund (IMF) to justify the strengthening of Neoliberalism in Argentina after the "2001 crisis". It considers a corpus of data composed by a pertinent sample of 59 articles published in Clarín newspaper analysed according to methodological tools for analysing discourse. It is expected that this task shall facilitate a reflection - with a greater degree of abstraction on the characteristics of an emerging "anti-neoliberal" discourse as a legitimising axis for the political agenda of officialism in Argentina.

Key words: (Anti-)neoliberalism, IMF, Political Discourse, External Debt, Financial Crisis.

\section{RÉSUMÉ}

Cet article présente et interprète les discours tenus durant le processus de négociation de la dette extérieure de 2003-2005, où les représentants du gouvernement argentin cherchèrent à inverser la logique argumentative employée par le Fonds monétaire international (FMI) pour justifier le renforcement du néolibéralisme dans le pays après la crise de 2001. L'on a utilisé un corpus de données composé d'un échantillon pertinent de 59 articles du journal Clarín, analysés à partir des outils méthodologiques de l'analyse du discours. Cela nous permettra de réfléchir, avec un plus grand degré d'abstraction, aux 
caractéristiques d'un discours « anti-néolibéral » émergent en tant qu'axe légitimateur des thèmes à l'ordre du jour dans la politique officielle argentine.

Mots-clés: (Anti-)néolibéralisme, FMI, Discours politique, Dette extérieure, Crise financière.

\section{摘要}

本论文对阿根廷政府在2003-

2005年外债谈判期间发表的多个官方声明进行分析解读，认为阿根廷政府利用了这些话语

推翻了国际货币基金组织

的在”2001年金融危机”

后的新自由主义的意识形态和辩论逻辑。论文使用了多种话语分析法(análise

dos discursos)，对59篇发表在CLARIN

日报上的文章进行了解读。通过解读，作者试图对阿根廷政府”反新自由主义”话语进行抽象 的反思, 对阿根廷政府利用反自由主义话语构建政治合法性的一些行为特点做分析研究。 关键字：(反-)新自由主义，国际货币基金组织(IMF)，政治话语，外债，金融危机

\section{I- Introducción}

La "crisis del 2001" fue una crisis económica pero también una crisis del sistema político, en general, y de las instituciones del gobierno del Estado argentino, en particular. En este contexto, el presidente Duhalde (2002-2003) fue capaz de asegurar un proceso de transición democrática relativamente ordenado, en parte porque logró estabilizar la economía y en parte porque era asociado, desde fines de los años 90, a un modelo de desarrollo distinto al activado por el menemismo.

No obstante ello, en la práctica, sus políticas siguieron en consonancia con muchas de las exigencias del FMI. En efecto, dispuso el pago puntual de intereses y capital de las deudas contraídas con los organismos multilaterales de crédito, reformó la ley de quiebras, adoptó un régimen cambiario de libre flotación y derogó la ley de subversión económica a partir de la cual se estaban investigando una amplia gama de actos ilícitos vinculados a la fuga de capitales, Kulfas y Schorr².

\footnotetext{
2 Kulfas, Matías y Martín Schorr (2003). La Deuda Externa Argentina: Diagnóstico y lineamientos propositivos 
Más importante aún, mantuvo congelados los salarios luego de la devaluación que puso fin al régimen de convertibilidad. Así, advierte Novaro, en los primeros seis meses del año 2002 los ingresos de los jubilados y empleados públicos perdieron cerca del 50\% de su poder de compra, en tanto los de la actividad privada, en promedio, cayeron alrededor del $20 \%$. La situación no estalló desde el punto de vista político "gracias al respaldo del sindicalismo, mayoritariamente alineado con el Ejecutivo"3.

Ahora bien, dicho respaldo no se extendió a los nuevos movimientos sociales. En junio de 2002, cuando el 51,4\% de los argentinos se encontraba por debajo de la línea de la pobreza, estos movimientos efectuaron una serie de movilizaciones que fueron duramente reprimidas por la Policía, Lozano ${ }^{4}$. La denominada "masacre de avellanada", ocurrida en el marco de una de estas movilizaciones, forzó al presidente a convocar a elecciones y a anunciar un aumento no remunerativo de 100 pesos en los salarios del sector privado, Rapoport ${ }^{6}$.

El recambio presidencial se realizó el 25 de mayo de 2003 e, inmediatamente, se iniciaron tratativas con el FMI tendientes a garantizar una salida ordenada del default. La oferta de canje argentina se hizo pública en el mes de setiembre previa firma de un acuerdo con esta institución. Sin embargo, las relaciones rápidamente se tensaron y hacia mediados de 2004, las nuevas autoridades nacionales decidieron continuar con el proceso de reestructuración de la deuda sin contar con el aval de las organizaciones multilaterales de crédito y en oposición a muchas de sus recomendaciones de política económica.

El presente artículo analiza las estrategias discursivas que, durante este proceso, los representantes del gobierno argentino activaron a la hora de invertir la lógica argumentativa desplegada por el FMI para justificar la profundización del neoliberalismo en el país. Se parte de presuponer que dicha tarea permitirá reflexionar, en un mayor

http://www.flacso.org.ar/uploaded_files/Publicaciones/240_AEYT_La.deuda.externa.argentina.pdf. Consulta: 01 de septiembre 2010.

${ }^{3}$ Novaro, Marcos (2006). Historia de la Argentina Contemporánea: de Perón a Kirchner, Buenos Aires: Edhasa, p. 296.

${ }^{4}$ Lozano, Claudio (2002). Catástrofe Social en Argentina: la situación a junio de 2002, Buenos Aires, Instituto de Estudios y Formación de la CTA: Ed. de la Universidad Nacional de La Plata, p. 299.

${ }^{5}$ La "Masacre de Avellanada" tuvo lugar el 26 de junio de 2002 y se recuerda en tanto en el marco de una manifestación de distintas organizaciones sociales resultaron asesinados a manos de la Policía Bonaerense dos jóvenes militantes, Maximiliano Kosteki y Darío Santillán.

${ }^{6}$ Rapoport, Mario (2010). Las políticas económicas de la Argentina. Una Breve Historia, Buenos Aires: Booket, p. 472. 
grado de abstracción, sobre las características de un emergente "discurso anti-neoliberal" como eje ordenador de la construcción de la identidad política del kirchnerismo naciente.

A estos efectos, se selecciona, de un universo de 586 artículos del diario Clarín relativos al canje de la deuda, una muestra de 59 artículos en los que se transcriben discursos o fragmentos de discursos de los principales voceros del Ejecutivo nacional pronunciados en respuesta a las exigencias del FMI y que son analizados, tal como se observa a continuación, a partir de herramientas propias del análisis del discurso ${ }^{7}$.

\section{II- Postulados teóricos-metodológicos de análisis: argumentos legitimadores de la orientación política del FMI en el escenario ex-post 2001}

¿En qué medida el análisis de los discursos asociados a estructuras institucionales determinadas (en este caso el aparato del Estado) permite comprender mejor los mecanismos de dichas instituciones, su naturaleza y sus transformaciones? Todo indica que hay niveles de funcionamiento de los procesos políticos a los que sólo podemos acceder a través del análisis de discurso. ${ }^{8}$

Wodak advierte que los discursos influyen tanto en los procesos políticos de carácter discursivo como en aquellos otros de carácter no discursivo: "en otras palabras, los discursos, en tanto que prácticas sociales lingüísticas, pueden considerarse como elementos que constituyen prácticas sociales discursivas y no discursivas, y al mismo tiempo, como elementos constituidos por ellas". 9

Esto último es fundamental para el presente artículo en tanto compele a pensar a lo discursivo no como una entidad derivada, posterior y causada por los acontecimientos políticos, sino como una de sus dimensiones inherentes. Visto así, explica Martínez ${ }^{10}$, la distinción entre discursos y realidad como dos fenómenos ontológicamente separados ya no es posible desde el momento en que los discursos son constitutivos de dicha realidad.

En consecuencia, la dimensión discursiva de las prácticas sociales no es simplemente aquello que traduce las luchas de poder dentro del campo político sino también aquello por lo que, y por medio de lo cual, se lucha. Se considera, desde allí, al canje de la deuda externa como un espacio particularmente propicio para analizar las

\footnotetext{
${ }^{7}$ En este trabajo los artículos del Diario Clarín se citan con la abreviatura "art." y el número que se identifica en el anexo.

${ }^{8}$ Verón, Eliseo (1987). Discurso Político. Lenguaje y Acontecimientos: la palabra adversativa, Buenos Aires: Hachette, p. 14.

${ }_{9}$ Wodak, Ruth (2003). "El enfoque histórico del discurso". In Wodak, R. y M. Meyer, Métodos de análisis crítico del discurso, Barcelona: Gedisa, p 104.

10 Martinez, Fabiana (Comp.). (2011). Lecturas del presente: discurso, política y sociedad, Villa María: Eduvim.
} 
disputas de sentidos que los agentes en el juego efectúan para imponer su visión particular del mundo como la legítima ${ }^{11}$.

Una de las categorías analíticas centrales en este cometido se refiere a la noción de "estrategias discursivas" que Wodak ${ }^{12}$ define como aquellas que surgen de un conjunto de prácticas más o menos interrelacionadas y más o menos intencionadas que un agente adopta con el fin de alcanzar un determinado objetivo. Las "estrategias argumentativas", que suponen una especificidad dentro de éstas, son aquellas a través de las cuales los hablantes categorizan, clasifican o definen las características de las personas o de las instituciones intentando fundamentar sus afirmaciones ${ }^{13}$.

La cualidad distintiva del discurso político se ubica en su carácter "polémico". La enunciación política es inseparable de la construcción de un "adversario". Esto significa:

que todo acto de enunciación política supone necesariamente que existen otros actos de enunciación, reales o posibles, opuestos al propio. En cierto modo, todo acto de enunciación política a la vez es una replica y supone (o anticipa) una réplica. Metafóricamente, podemos decir que todo discurso político está habitado por Otro Negativo. Pero como todo discurso, el discurso político construye Otro Positivo, aquél al que el discurso está dirigido. En consecuencia, de lo que se trata en definitiva es de una suerte de desdoblamiento que se sitúa en la destinación. Podemos decir que el imaginario político supone no menos de dos destinatarios: uno positivo y otro negativo. El discurso político se dirige a ambos al mismo tiempo. ${ }^{14}$

El destinatario positivo, continúa el autor, es esa posición del campo que corresponde a un receptor que participa de las mismas ideas, adhiere a los mismos valores y persigue los mismos objetivos que el enunciador: es ante nada el partidario o prodestinatario. La relación entre ambos cobra en el discurso político, la forma característica de una entidad que se llama "colectivo de identificación" y que se expresa en un "nosotros" inclusivo.

El destinatario negativo está, por supuesto, excluido de dicho colectivo: de hecho, esta exclusión es la definición misma de este contradestinatario. El lazo con éste reposa, por parte del enunciador, en la hipótesis de una inversión de la creencia: lo que es verdadero o bueno para el enunciador es falso o malo para el contradestinatario e inversamente; "ese otro discurso que habita todo discurso político no es otra cosa que la

\footnotetext{
11 Ambort, Matilde (2011). "Fundamentos discursivos del programa Familias por la Inclusión Social. Hegemonía discursiva neoliberal: ¿continuidades o rupturas?". In Martinez, F. Lecturas del presente: discurso, política y sociedad, Villa María: Eduvim, p. 52.

${ }_{12}$ Wodak, R. (2003). Op. Cit., p. 115.

${ }^{13}$ Vasilachis, Irene (2003). Pobres, pobreza, identidad y representaciones sociales, Barcelona: Gedisa, p. 101.

${ }^{14}$ Verón, E. (1987). Op. Cit., p. 16.
} 
presencia, siempre presente, de la lectura destructiva que define la posición del adversario". ${ }^{15}$

Nos hemos detenido en esta breve caracterización porque en el caso concreto interesa analizar las cualidades que el discurso del gobierno kirchnerista atribuyó al FMI ("contra-destinatario") a lo largo del proceso de canje y las estrategias discursivas que utilizó para invertir su lógica argumentativa destinada a legitimar su actuación en el escenario ex-post 2001. Se parte de presuponer que dicha tarea permitirá dar cuenta de las aptitudes que el gobierno atribuyó a sus "pro-destinatarios" en la construcción de su identidad política.

Esta actuación del FMI sólo puede comprenderse en función de su participación en el proceso de reforma de los años 90. En efecto, durante estos años, la institución firmó cinco acuerdos financieros consecutivos con las autoridades argentinas y convirtió al país en su tercer deudor a escala global. Así, hacia el momento del estallido de la crisis, su prestigio estaba hondamente asociado a la continuidad del régimen de convertibilidad al cual desde hacía algún tiempo consideraba especialmente viable y un ejemplo para otros Estados de desarrollo intermedio. ${ }^{16}$

“¿Porqué la nación que siguió las reglas cayó en pedazos?” Se preguntaba Stiglitz ${ }^{17}$ a días de producirse el default en Argentina ¿Que había pasado? ¿Cómo el país qué más había avanzado en la reforma neoliberal de su Estado caía en un pozo tan profundo? ¿Cómo se había producido ese desenlace cuando los organismos multilaterales de crédito controlaban palmo a palmo la economía nacional y otorgaban miles de millones de dólares para que el gobierno escapase de la recesión?

Enmarcado en estos interrogantes, los representantes del FMI iniciaron un proceso de revisión del grado de avance de las autoridades argentinas en cada una de las áreas de reformas por ellos propiciadas arribando a la conclusión de que éstas se habían alejado, en aspectos puntuales pero significativos, de las medidas necesarias para asegurar el crecimiento, Manzo y González Salva ${ }^{18}$. La crisis se desencadenó,

\footnotetext{
${ }^{15}$ Ibidem, p. 17.

16 Takagi, Shinji y otros (2004). Informe sobre la evaluación del Papel del FMI en Argentina, 1991-2001, Oficina de Evaluación Independiente del FMI. Disponible en: http://www.ieoimf.org/eval/complete/pdf/07292004/espanol.pdf. Consulta: 01 de septiembre 2010.

17 Stiglitz, Joseph (2002). Argentina, de vuelta el cambio completo: ¿Porqué la nación que siguió las reglas estalló en pedazos. Disponible en: http://www.yorku.ca/robarts/archives/institute/2002/stiglitz_argentina.pdf. Consulta: 01 de septiembre 2010, p. 1.

18 Manzo, A. G. y González Salva, C. (2012). "La crisis del neoliberalismo en Argentina. Una mirada retrospectiva sobre las causas del default 2001. Buscando razones para entender el quiebre de nuestro país
} 
básicamente, por un excesivo gasto fiscal primario en un contexto internacional adverso para la viabilidad del régimen de convertibilidad ("explicación fiscalista de la crisis"). El principal error del FMI en el país, señalaron Mussa ${ }^{19}$ y Krueger $^{20}$, fue el de no haber sido lo suficientemente riguroso en el control del cumplimiento de las condicionalidades exigidas.

Partiendo de estas premisas -observaron- la institución, en el escenario ex-post 2001, no debía otorgar más financiamiento a Argentina hasta tanto ésta no implementase las reformas consideradas como prioritarias para estabilizar la economía. Los agentes financieros internacionales, advertía Mussa $^{21}$ en este sentido, aún conservan: "[...] un enorme peso sobre la voluntad de las autoridades nacionales, y si es necesario, deberán usarlo para ayudar a que las quejas externas lleguen a buen puerto".

Este peso fue puesto a prueba en el marco de la renegociación de la deuda en default. La discusión entre el gobierno y el FMI giró, primordialmente, en torno al grado y tipo de "ajuste fiscal". El presidente Kirchner, al inicio de las tratativas, fijó un techo del 3\% del PBI con destino al pago de los acreedores externos. En la práctica, esto significaba una quita promedio del $75 \%$ de los bonos defaulteados en negociación cuyo monto ascendía a más de 80 mil millones dólares. El FMI, por su parte, consideró que este porcentaje debía aumentarse, al menos, hasta el 4 o 5\% del PBI lo que implicaba un mayor ahorro por parte del Estado y, consecuentemente, una mayor reducción del gasto público $^{22}$.

Los "ajustes" -que suponen recortes en salarios, planta de personal, seguridad social, subsidios y regímenes de promoción industrial- se ubican, desde la década de los 80 , en el centro mismo de los programas financieros de los organismos multilaterales de crédito. Estos, desde el punto de vista de sus promotores, se justifican de manera relativamente sencilla. En efecto, buscan administraciones estatales eficientes y racionales que eviten malgastar recursos en momentos de recesión. Procuran, de igual modo, controlar el déficit fiscal y prevenir posibles brotes inflacionarios.

con el FMI". In Passagens: Revista Internacional de Historia Política y Cultura Jurídica, Universidad Federal Fluminense, v. 4, n. 2, mayo-agosto, p. 299-327.

${ }_{19}$ Mussa, Michael (2002). Argentina y el Fondo: Del Triunfo a la Tragedia. Disponible en: http://bookstore.piie.com/book-store//343.html. Consulta: 01 de septiembre 2010.

${ }^{20}$ Krueger, Anne (2002). "Prevención y Solución de Crisis: Lecciones desde Argentina". In Conferencia sobre la "Crisis Argentina", Cambridge, 17 de Julio, Disponible en: http://cdi.mecon.gov.ar/biblio/docelec/nber/books/Arg/krueger.pdf. Consulta: 01 de septiembre 2010.

${ }^{21}$ Mussa, M. (2002). Op. Cit., p. 65.

${ }^{22}$ Manso, A. G. (2012). Op. Cit. 
Más importante aún, estos ajustes, son la clave que posibilita la correcta inserción del país al mercado financiero internacional. Esto es así, en tanto el ahorro por ellos producido se destina al pago de los acreedores externos con el objeto de poner fin a la situación de anormalidad que la recesión supone y alejar el peligro de un posible default. Una vez, que la economía local se haya estabilizado, y que la credibilidad y la confianza internacional se hayan recuperado, advierten sus promotores, el país será nuevamente destinatario del crédito externo y podrá recibir las inversiones privadas necesarias para asegurar el crecimiento a mediano y largo plazo; crecimiento, cuyos beneficios, en última instancia, se derramarán sobre todos los estratos sociales (vgr. "teoría del derrame") 23.

Se traza, de esta manera, un círculo argumentativo lógico que ata en relación de continuidad a los recortes del gasto público, por un lado, con los acreedores externos y, por otro, con los intereses de la sociedad en su conjunto. Subyacen en esta narrativa presupuestos básicos del neoliberalismo. El Estado se minimiza y deja de ser considerado el motor de la economía; antes bien, en su tamaño excesivo se encuentra la causa de la crisis que se afronta y en su recorte la solución. Su papel, en consecuencia, debe limitarse a garantizar un libre flujo de capitales y a transferir recursos hacia los agentes que operan en el marco del mercado financiero internacional; serán, precisamente, estos agentes los encargados de promover el desarrollo y el bienestar general.

El círculo se cierra agregando a estos elementos el "rol del FMl". Este, en esta lógica, se presenta como "coordinador" de los procesos de negociación entre los gobiernos fuertemente endeudados y sus acreedores. Exige a los primeros ajustes estructurales y a los segundos que refinancien sus acreencias y participen en los paquetes de financiamiento de rescate. Estos paquetes, a los que el propio organismo contribuye y cuyos fondos se destinan -también- al saneamiento del sistema financiero, se entienden como decisivos en lo que a la recuperación económica se refiere desde el momento en que, por un lado, constituyen el único acceso a recursos líquidos que el gobierno posee en estos contextos y, por otro, envían a los operadores financieros una señal de que el mercado local se halla avalado por la comunidad internacional. Dicho aval, al igual que el desembolso de las divisas, aparece supeditado al cumplimiento

\footnotetext{
23 "Para el FMI, cuánto más dinero se destine al pago de la deuda y más rápido se normalicen las relaciones con los acreedores, mayor será el crecimiento: prometen, dice un periodista del diario Clarín al momento de reportar las negociaciones en el canje, que vendrán inversiones y se reanudará el crédito internacional Disponible em: http://edant.clarin.com/diario/2003/09/09/p-00603.htm. Consulta: 10 de agosto 2012-".
} 
efectivo por parte de las autoridades nacionales de las condicionalidades requeridas por la institución.

A continuación se presenta la lógica argumentativa de los discursos de los voceros del Ejecutivo nacional en el canje tendientes a revertir esta construcción discursiva. Es relevante advertir en este sentido que, desde el inicio mismo de las negociaciones, éste planteó una estrategia discursiva de confrontación a la posición del FMI. Se trató, efectivamente, de un discurso frontal y franco que tendió a polarizar intereses y en el cual la cooperación propia de las tratativas se minimizó para resaltar su carácter "conflictual"; de "lucha de poder" entre agentes que se construyeron desde el propio discurso como antagónicos. Como bien explicó una "fuente"24 al diario Clarín, Kirchner a través de esta estrategia pretendió tensar al máximo las relaciones con los acreedores pero sin romper la cuerda y en caso de que ello sucediese, demostrar que la ruptura no aconteció por su culpa.

\section{III- La estrategia discursiva del gobierno nacional en acción: inversiones a la lógica argumentativa del FMI en el marco del canje de la deuda externa en default}

\section{1- El neoliberalismo como "causa" de la crisis del 2001: la responsabilidad del FMI.}

Los organismos multilaterales y el FMI tienen que hacer su autocrítica porque fracasamos los argentinos pero fundamentalmente fracasó un proyecto económico, financiero y social que el FMI dio y asesoró a los gobernantes argentinos de ese momento -Kirchner, art.56-.

A través del análisis de este párrafo pueden introducirse una serie de nociones generales que cortan transversalmente el discurso del gobierno nacional a lo largo del proceso de canje. A continuación se desglosa, resaltando las diferencias existentes entre este discurso y aquél de los representantes del FMI brevemente descrito.

Lo primero a observar en esta dirección es que existe una asociación discursiva inmediata entre los "organismos multilaterales" de crédito y un "proyecto económico, financiero y social" que se implementó en Argentina en el pasado inmediato. Este proyecto, al que el presidente alude, puede con certeza inferirse, es el proyecto neoliberal.

A través de esta asociación el gobierno otorga materialidad a una ideología que de otra manera se mantendría en el plano de la abstracción en un doble sentido interrelacionado: el neoliberalismo, por un lado, no se presenta como un conjunto de

\footnotetext{
${ }^{24}$ El informante del Diario Clarín fue calificado en términos de "un íntimo del Presidente" -art.10-.
} 
ideas desorganizadas y sumamente vagas sino por el contrario como un "proyecto" de aplicación práctica y de vasto alcance -“económico, financiero y social"- y, por otro, tiene cara visible en las organizaciones multilaterales de crédito; dentro de las cuales, el FMI es individualizado y resaltado por el primer mandatario.

El Fondo aparece así y desde el inicio como el máximo referente del neoliberalismo en los discursos del gobierno hasta el punto tal que, y como se verá, los límites entre esta institución y la ideología que promueve se tornan difícilmente identificables. El FMI se presenta como el agente encargado de diseñar esta clase de proyectos y con capacidad para difundirlos a través del mundo; como aquél que, en palabras de Kirchner, "dio" el neoliberalismo a la Argentina y "asesoró" a los gobiernos nacionales que lo implementaron. De allí que, durante el canje, el presidente haya exigido una y otra vez: "[...] al FMI que "asuma la cuota de responsabilidad de haber alentado las políticas que llevaron a la Argentina al colapso económico del año 2001" -art. 7-.

El Ejecutivo nacional invierte en estos términos la "explicación fiscalista de la crisis" dada por el FMI desde el momento en que lo que llevó a "Argentina al colapso económico del año 2001" no fue, desde su perspectiva, un excesivo gasto público si no las "políticas" de corte neoliberal que se aplicaron en el país desde la década del 70 en adelante.

Es mentira, dijo en este sentido la legisladora y primera dama Cristina Fernández de Kirchner, que lo de 2001 haya empezado un año antes, ni siquiera empezó cuando comenzó el gobierno de Menem. Tuvo sus orígenes mucho más alejados, el 24 de marzo de 1976; ése fue el punto de inflexión en la sociedad argentina -art. 41 -.

De esta construcción discursiva se desprende de manera inmediata, y ésta es la segunda inversión a la lógica expuesta en el acápite anterior, la responsabilidad, o más correctamente, la co-responsabilidad del Fondo por lo sucedido en nuestro país; "porque fracasamos los argentinos pero fundamentalmente fracasó" el proyecto implementado. Obsérvese que a partir de estas palabras el presidente tasa las cuotas de responsabilidad por lo acontecido. Los argentinos y el FMI no poseen cuotas de responsabilidades semejantes; los argentinos fracasamos pero lo que fracasó fue "fundamentalmente" el proyecto que esta institución dio al país. "Nos hacemos cargo de la adopción de políticas ajenas que nos llevaron al peor de los mundos. Pero no basta con la simple aceptación por parte de los organismos multilaterales de crédito respecto de su error al aconsejarlas, exigirlas y apoyarlas" -Kirchner, art. 32-. 
El fragmento citado refuerza las nociones hasta aquí presentadas. El gobierno reconoce la responsabilidad de los argentinos en los acontecimientos, pero dicha responsabilidad proviene de "la adopción de políticas ajenas". Dicho en otros términos, lo que nos llevó "al peor de los mundos" posibles, desde esta lógica argumentativa, fue la adopción de políticas neoliberales. Los organismos multilaterales de crédito poseen, en el párrafo transcripto y a este respecto, una cuota de responsabilidad mayor que la de los propios argentinos que deriva de su error de "aconsejar" y "apoyar" este tipo de políticas; más aún, de "exigirlas". Por ello, no basta con "la simple aceptación" de su "error"; ellos, dice el presidente a continuación, deberán hacer su "mea culpa" y efectuar una serie de "reformas estructurales" en la orientación de sus prácticas precedentes -art. 32-.

La prueba directa y más palpable de dicha responsabilidad es en el discurso del primer mandatario el default de la deuda externa cuyo canje está presentado:

[...] el gran crecimiento del endeudamiento argentino se dio con la gestión de Martínez de Hoz y se profundizó paulatinamente con los gobiernos democráticos pero se potenció fuertemente en la década del 90 generando un endeudamiento que es realmente incomprensible" y concluyó "cuando alguien mira el nivel de lo que se debe y cómo está Argentina, nadie puede entender dónde se invirtió esa plata, dónde está -art. 9-.

La deuda aparece de este modo, en palabras del presidente, como el eje que corta transversalmente al período de hegemonía neoliberal en el país, que arranca con el primer ministro de la dictadura (Martínez de Hoz) y se extiende durante las décadas subsiguientes. Este endeudamiento es presentado, por un lado, como "incomprensible", es decir como carente de sentido, desde el momento en que no existe relación entre "lo que se debe" y "cómo está la Argentina" en el escenario inmediatamente posterior a la crisis del 2001 y, por otro, como ilegítimo, como oscuro o fraudulento, en tanto "nadie puede entender dónde se invirtió esa plata, dónde está" el dinero que se debe.

Este hincapié del gobierno por develar el origen y la naturaleza de la deuda externa, que es constante a lo largo de todo el proceso de renegociación, procura no sólo legitimar su propuesta de canje sino también atarla a la crisis del 2001 en el marco de la cual se decretó el default. Y aquí, el papel de los organismos multilaterales de crédito es central en su discurso, ya que "aguantaron a gobiernos tan poco serios durante tanto tiempo, les prestaron tanta plata y pasó tanta vergüenza la Argentina -art. 17-” observó Kirchner y agregó: 
[...] había algunos funcionarios de esos organismos que durante muchos años estuvieron asesorando muy mal a la Argentina. Porque no llegamos a esta situación solamente por los errores argentinos y el desgobierno. Recuerden que en muchos casos se amparaban a gobiernos que decían que eran muy buenos (cuando en realidad no lo eran) -art. 9-.

De esta manera, la corresponsabilidad de los organismos multilaterales en el proceso de endeudamiento deviene -en esta construcción discursiva- no de una actitud meramente pasiva sino, por el contrario, de una acción positiva; no sólo sabían y permitían que los gobiernos argentinos se endeudaran de manera "incompresible" sino que ellos mismos promovían dicho endeudamiento en tanto eran ellos los que los asesoraban. Dicho asesoramiento, que se produjo "durante muchos años", es calificado por el presidente como equivocado, como "muy malo". Kirchner, finalmente, va un paso más allá al señalar que estas instituciones "amparaban" a los gobiernos argentinos de entonces y "decían que eran muy buenos" cuando en realidad, se infiere, no lo eran. Estas acciones de "amparo" y "promoción" -que transcienden al mero asesoramiento-, cobran una significación especial en el caso en tanto estaban destinadas a dotar de credibilidad al país en los mercados de capitales y a atraer hacia éste las divisas fuente del endeudamiento.

La lógica del discurso del gobierno en este punto se completa al observar que el grueso de estas divisas no se utilizó, de conformidad a su postura, para el desarrollo y el crecimiento del país sino para que determinados agentes obtuvieran enormes ganancias en el marco del propio mercado financiero. De allí que, asocie a los acreedores de la deuda que se negocia con prácticas especulativas y al neoliberalismo con el modelo económico social que promueve este tipo de prácticas.

Por primera vez en la historia, la operación ha culminado con una drástica reducción de la deuda del país" observó Kirchner a días de finalizado el canje e, inmediatamente, "arremetió contra lo que definió como las políticas erradas del pasado [...] no debemos crear riqueza a partir de la nada, sino a partir de la producción -art. 50- o, en términos del ministro de economía, Lavagna, no debemos "crear dinero jugando con el dinero. ${ }^{25}$

\section{2- Los ajustes no “fomentan" la recuperación económica; antes bien la "previenen”}

${ }^{25}$ Lavagna, Roberto (1999). Neoconservadurismo vs Capitalismo Competitivo, Buenos Aires: Fondo de Cultura Económica, p. 17. 
Durante su primer contacto personal con el director gerente del Fondo, a días de su asunción, el presidente señaló no estar "dispuesto a aplicar ajustes en perjuicio de la población -art. 1-". Meses después, Kirchner, dice el diario Clarín, cargó:

[...] sobre los "sectores dentro de la propia Argentina, el neoliberalismo, que dicen que hay que hacer más ajustes o dar más superávit fiscal primario para poder ordenar la situación y que vengan los capitales". Insistió en atacar esos argumentos con una frase que ya convirtió en usual: "ya vimos lo que nos pasó a los argentinos en cuanto a los niveles de desocupación, indigencia y pobreza" -art. 9 -.

Lo primero a observar del párrafo transcripto es que existe -en el discurso del gobierno- una asociación entre los ajustes estructurales prescriptos por el Fondo como estrategia de fomento económico en momentos de recesión y los efectos de pauperización social que el país atravesó desde fines del siglo XX en adelante.

Se trata de una construcción discursiva que coincide con la posición de los denominados "críticos heterodoxos" a la intervención del FMI en los países afectados por una crisis financiera y que se encontraba ampliamente difundida en Argentina después de lo acontecido en el año $2001^{26}$. Para estos críticos los ajustes estructurales no revierten las crisis financieras, por el contrario las causan:

muchos economistas americanos sugieren que la crisis hubiera sido evitada si la Argentina hubiese seguido las recetas del FMI rigurosamente; en especial recortando el gasto primario (incluido en el nivel provincial) más fuertemente. Muchos latinoamericanos, sin embargo, piensan que el cumplimiento del plan completo del FMI los hubiese llevado a una crisis aún peor. Creo, dice Stiglitz ${ }^{27}$ (2002), que los latinoamericanos son quienes tienen razón ${ }^{28}$.

Este nexo discursivo entre "ajuste" y "ahogo" de la recuperación económica, fue puesto en evidencia por el presidente argentino al advertir que:

\footnotetext{
${ }^{26}$ Hacia finales del siglo $\mathrm{XX}$, y luego de las crisis financieras que azotaron a distintos países de desarrollo intermedio, el FMI se encontraba bajo ataque desde distintos sectores. Kulfas y Schorr (2003) utilizan la denominación "críticos heterodoxos" para diferenciarlos de los "críticos ortodoxos" que cuestionaban la actuación de la institución en los mercados emergentes desde presupuestos propios del neoliberalismo y que habían cobrado fuerza a partir de la llegada de Bush al gobierno de los EEUU.

${ }^{27}$ Stiglitz, J. (2002). Op. Cit., p. 1.

${ }^{28}$ En su exposición frente a la comisión del congreso norteamericano encargada de analizar la crisis argentina, Weisbrot señaló: "el FMI debe interiorizar que jugó un extendido rol en causar la actual crisis de la economía argentina. Esto es mucho más que un mero registro histórico. Es necesario prevenir que el Fondo cause más daño. Por ejemplo, Argentina ha estado en recesión por casi cuatro años. Durante este período, el Fondo ha apoyado, con préstamos y presiones políticas, ajustes fiscales en el presupuesto del gobierno central. Esto es algo que los economistas de los EEUU nunca recomendarían para nuestra economía durante una recesión, y ha indudablemente empeorado y/o prolongado la depresión en Argentina" (Weisbrot, Mark (2002). Declaraciones ante el Subcomité en Política Monetaria y Comercial Internacional del Comité de Servicios Financieros de la Cámara de Diputados del Congreso de los EEUU, la crisis económica argentina: causas y remedios. Disponible en: http://Financialservices.House.Gov/Media/Pdf/10752.Pdf. Consulta: 01 de septiembre 2010, p. 44).
} 
[...] la economía nacional "necesita liquidez para la reactivación" porque "cualquier acuerdo tiene que servir para consolidar el proceso de reactivación que está pidiendo la Argentina con el crecimiento del empleo, el consumo y las exportaciones [...] "y justificó esta postura al señalar que lo que el gobierno no quiere es que "pase lo que les pasó a Machinea y a De La Rua" -art. 8-.

El discurso del ejecutivo nacional invierte, de este modo, la concepción del FMI en lo que al rol del Estado en la sociedad se refiere. Esto es así, en tanto, en el párrafo transcripto, ata la "reactivación" de la economía argentina, no al ahorro y al pago de la deuda externa como lo hacen los representantes de esta institución, sino, por un lado, a una política estatalmente expansiva que otorgue "liquidez" al mercado y, por otro, al "crecimiento del empleo, el consumo y las exportaciones". Ambos extremos, es relevante aclararlo, se encuentran en relación de continuidad en la medida en que, para esta lógica argumentativa, la liquidez proveniente del Estado fomenta el crecimiento del empleo, el consumo y las exportaciones y, viceversa; este crecimiento aumenta la recaudación fiscal posibilitando la expansión del gasto público ${ }^{29}$.

El camino contrario, entiende Kirchner, vinculado a su contracción, llevan a "lo que les pasó a Machinea y a De La Rua" en clara alusión a lo acontecido en la crisis del 2001:

[...] cuando los superávit se logran merced a la eliminación de las inversiones en infraestructura física o social se afectan de tal modo la posibilidad de sustento político y el crecimiento que termina por hacerse de algo virtuoso un instrumento de desequilibrio negativo para el país y para el funcionamiento global de la economía -art. 32-.

El primer mandatario refuerza en estos términos la postura del gobierno en relación a las políticas recomendadas por el FMI. Los ajustes, que se logran merced a la "eliminación de las inversiones en infraestructura física o social", lejos de tender al equilibrio del país y al correcto funcionamiento global de la economía, observa, afectan no sólo el "crecimiento" sino también el "sustento político" de los países insertos en una situación de crisis ${ }^{30}$.

Para comprender el porqué de esta argumentación es necesario mencionar que de conformidad a la postura del Ejecutivo nacional en el canje: "si ponemos, dijo Kirchner, un

\footnotetext{
${ }^{29}$ Rapoport, M. (2010). Op. Cit., p. 477.

${ }^{30}$ La cita es relevante en cuanto diluye los límites entre el campo económico y político rompiendo con ello con la lógica de un discurso tecnocrático que los tiende a separar, enmascarando el contenido político de la economía y justificando las decisiones gubernamentales en términos meramente técnicos (Reynares, Juan M. (2011). "El discurso tecnocrático y las huellas de la hegemonía neoliberal". In Martinez, F. (2011). Lecturas del presente: discurso, política y sociedad, Villa María: Eduvim,p. 29-50).
} 
superávit fiscal primario más alto del que hemos ofrecido pagar, que es del tres por ciento, eso se paga con más ajuste, con más hambre -art. 9-". Las políticas del FMI minan -en su discurso- el crecimiento económico y el sustento político porque, a diferencia de lo que postulan sus promotores, éstas no se traducen en mayor bienestar para la población argentina sino, por el contrario, en mayor "hambre".

De allí que, el presidente se queje una y otra vez "por el hecho de que existan "inclusive dentro del propio país, algunos que quieren que se reiteren las fórmulas del pasado".

Fórmulas del pasado en el que se hicieron acuerdos internacionales que casi nunca se cumplieron, pero que se hicieron sobre fuertes ajustes de la población argentina, que generó exclusión social, que generó exclusión institucional, que generó hambre, que generó el quiebre de la industria y de los empresarios nacionales" remarcó. Pidió al pueblo que tenga "buena memoria de esto" -art. 9-.

En este cita el primer mandatario agrega una serie de efectos a los ya mencionados que son necesarios enumerar; estas "fórmulas del pasado", que se infiere con certeza son las políticas de corte neoliberal cuya implementación el FMI recomienda en el escenario ex-post 2001 y "que se hicieron sobre fuertes ajustes de la población argentina", para esta construcción discursiva, supusieron: a) "acuerdos internacionales que casi nunca se cumplieron", situación que llevó al desprestigio del país en el exterior; b) "exclusión social", un vocablo vinculado al estado de pobreza pero que trasciende lo meramente económico; c) "exclusión institucional", cercano a lo anterior, pero relativo específicamente a la marginalización que sufrieron sectores de la población en relación a las instituciones del Estado; d) "el quiebre de la industria y de los empresarios nacionales", relativo a los procesos de des-industrialización que vivió el país y una de las principales causas del desempleo.

Partiendo de estos presupuestos, el presidente llama al "pueblo" argentino a tener "buena memoria de esto". Adviértase que los sectores que promueven el neoliberalismo en Argentina no forman parte del "colectivo de identificación" al cual su discurso se dirige; o dicho en otros términos, estos sectores, aún cuando se hallen "dentro del país", no forman parte -en la narrativa del primer mandatario- del "pueblo" argentino ${ }^{31}$.

\footnotetext{
${ }^{31}$ La palabra utilizada para efectuar dicho llamado, "memoria", tiene una carga simbólica particular para el kirchnerismo naciente en tanto está asociada a su posición con respecto a los crímenes de lesa humanidad cometidos durante la última dictadura militar.
} 
El gobierno traza en estos términos un límite entre el pasado y el presente, entre el adentro y el afuera, que desafía la concepción ortodoxa previamente expuesta. Bajo esta concepción, como ya se mostró, mientras más dinero se destine al pago de la deuda externa mayores serán los beneficios para la población argentina en su conjunto (vgr. "teoría del derrame"). Para el discurso de las autoridades nacionales en cambio, la atención de las obligaciones internacionales en default debe compatibilizarse e, incluso, subordinarse al pago de la "deuda interna". Nuestro plan, expresó Kirchner en este sentido: "es mantener el equilibrio fiscal y lograr un superávit fiscal primario para saldar la deuda interna y afrontar razonablemente los pagos externos "[...] Aclaró además que "la negociación con el FMI no se establece en términos de pedir fondos frescos" -art. 7-.

Esta inversión discursiva que efectúa el gobierno argentino de las prioridades en el canje ataca el centro mismo de la lógica neoliberal presentada. El FMI, cabe recordar, legitima su política económica en función de la correcta integración del país al mercado financiero internacional. Para el discurso del Ejecutivo nacional, por el contario, la atracción de capitales externos no constituye un "fin en sí mismo". Más aún, y dadas las circunstancias históricas concretas, las negociación con el Fondo, observa el presidente, "no se establece en términos de pedir fondos frescos". De allí que, para su postura, deba mantenerse "el equilibrio fiscal y lograr un superávit fiscal primario" para saldar, en primer término, la "deuda interna" y, en segundo término, "afrontar razonablemente los pagos externos".

\section{3- En la práctica, el neoliberalismo constituye una doctrina económica social tejida en torno a la satisfacción de determinados "intereses"}

Los representantes argentinos y los del FMI firmaron un programa financiero en el mes de septiembre de 2003. Para sorpresa de muchos, teniendo en cuenta que la misión de la institución encargada de revisarlo se retiró del país sin hacer observaciones, se pospuso la aprobación de su primera revisión. En este contexto, el presidente Kirchner sostuvo: "[...] los integrantes de la burocracia del Fondo son empleados de intereses $y$ son responsables de la crisis argentina. Y fue por más: "prácticamente esquilmaron a la Argentina con errores y, ahora que estamos saliendo, nos quieren condicionar" -art. 17-.

En este párrafo puede visualizarse que el primer mandatario argentino invierte al menos tres ideas básicas de la ideología neoliberal brevemente expuesta. En primer lugar, asocia discursivamente al FMI con determinados "intereses" desafiando de esta 
manera el carácter a-político y meramente técnico con el cual la institución se presenta y justifica la implementación de reformas de corte neoliberal. En segundo lugar, utiliza la palabra "burocracia", con una connotación peyorativa, para hacer referencia a que las acciones de sus integrantes no son verdaderamente autónomas; no surgen, como sus promotores advierten, de su propia voluntad sino que se deciden en cumplimiento de órdenes (vgr. son "empleados"). En tercer lugar, observa que dichos integrantes "nos quieren condicionar". El FMI, desde esta lógica argumentativa, constituye un organismo que no sólo "coopera" con los gobiernos de sus países miembros sino también uno con capacidad para "condicionarlos", lo que supone de suyo la existencia de relaciones desiguales de poder que se encuentran ausentes en los discursos oficiales del organismo. Es por ello que solicita: "[...] un urgente, fuerte y estructural rediseño del FMI para que pueda prevenir crisis y ayudar a su solución, cambiando el rumbo que lo llevó de prestamista de fomento a acreedor con demanda de privilegios" -art. 32-.

El análisis de esta cita permite comenzar a develar a qué "intereses" -considera el gobierno nacional- responden los integrantes del FMI y que lo llevaron de "prestamista de fomento" antes de la crisis del 2001 a "acreedor de privilegio" luego de ésta. Para comprender el porqué de esta cambio de "rumbo" es necesario advertir que el programa referido se aprobó a partir de un proceso decisorio especial en el cual las autoridades argentinas y las del Fondo, sin ponerse de acuerdo en relación a la "meta fiscal" a cumplir, giraron un borrador a los representantes de los países del G7 para que estos decidiesen al respecto ${ }^{32}$. Estos apoyaron la propuesta argentina "del 3\% del PBI" a condición de que los organismos multilaterales se convirtiesen en acreedores privilegiados de Argentina, tal como efectivamente aconteció.

El presidente pretende poner en evidencia, así y a partir de una situación concreta, que -para las autoridades argentinas- las decisiones de la institución no se fundamentan en principios económicamente abstractos y beneficiosos para la población en la cual interviene, tal como lo postulan sus promotores, sino por el contrario en los intereses de sus principales accionistas. El FMI requiere, consecuentemente, un "urgente, fuerte y estructural rediseño" para que su orientación política sea capaz de "prevenir las crisis y ayudar a su solución" y evitar cambios de rumbo a favor de los gobiernos de las potencias occidentales (vgr. G7).

\footnotetext{
${ }^{32}$ En el caso concreto, los países del G7 eran: EEUU, Inglaterra, Alemania, Francia, Japón, Italia y Canadá.
} 
Ahora bien, estos gobiernos, para la construcción discursiva del Ejecutivo nacional en el canje, no representan sus únicos beneficiarios: "[...] hay un sector del Fondo que "vive sorprendiéndose con los indicadores de la economía", pero lo que realmente "quieren es que el superávit sea más grande para pagarle más a los acreedores" Lavagna, art. 18-.

El ministro, con estas palabras, refuerza las nociones hasta aquí presentadas atacando el carácter desinteresado del organismo al cuestionar si sus verdaderas funciones son aquellas que exhibe a partir de sus discursos 0 , en realidad, otras que se vinculan a la defensa de determinados capitales económicos. En efecto, de conformidad a su lógica, Argentina "sobre-cumplió" las metas fijadas en el acuerdo de setiembre hasta el punto tal de que hay un "sector del Fondo que "vive sorprendiéndose con los indicadores de la economía"'. Este sector, en el discurso de Lavagna, es aquel vinculado a los intereses de los agentes financieros privados que, entendiendo vulnerados sus derechos, comenzaron a presionar para que se modifique la situación de privilegio de la banca oficial del G7.

Se sigue desde allí, que lo que "realmente" quiere el FMI a partir de su decisión de posponer la aprobación de la primera revisión es -de acuerdo al relato del gobierno en el canje- "que el superávit sea más grande para pagarle más a los acreedores" privados. Se trata de una cita relevante en tanto cuestiona la capacidad del organismo para "coordinar" esta clase de procesos desde el momento en que ésta no constituye una institución equidistante entre ambas partes en tratativas sino, desde esta construcción discursiva, una entidad que opera como representante o promotor de los intereses de sólo una de ellas: "los acreedores".

[...] cuando nos dicen que hay que compensar los amparos que tuvieron que pagar los bancos, me pregunto: si hablamos de compensar, en un país que tiene el 50 por ciento de pobreza, que tiene los niveles de indigencia que tenemos, ¿A cuántos hay que compensar para poder alcanzar los equilibrios? -art. 9-.

El párrafo transcripto no se opone al anterior sino que lo precisa y lo complementa. De una parte, porque a partir de estas palabras, el presidente procura mostrar que las políticas del FMI buscan, en última instancia, "compensar a los bancos" por las pérdidas que sufren en las crisis financieras ${ }^{33}$. De otra parte, porque traza un nexo discursivo entre

${ }^{33}$ Es relevante advertir que para el gobierno argentino los grandes bancos transnacionales poseen una cuota de responsabilidad relativamente importante en la crisis del 2001 en tanto son considerados agentes especulativos que, por un lado, aumentaron la deuda externa para su propios beneficios, y por otro, fugaron 
dicha compensación y los profundos efectos de pauperización social que esta clase de crisis traen aparejados; nexo que la lógica neoliberal disocia. En efecto, los ajustes no se hacen en perjuicio/beneficio de "toda" la población. Los ajustes, desde esta construcción, transfieren recursos desde el pueblo argentino, en un momento en el cual -dice el presidente- existe un "50 por ciento de pobreza", a los agentes financieros; o lo que es lo mismo, estos ajustes socializan las pérdidas de los grandes capitales transfiriendo los costos de la crisis a los sectores sociales más afectados por ella. De allí que exprese: "[...] ahora son al revés: antes, en cada discusión el ajuste era para adentro". "Era muy fácil ser fuerte con los débiles y ser débiles con los poderosos" -art. 26-.

El primer mandatario subraya, de este modo, el límite discursivo trazado entre el pasado "neoliberal" y el presente-futuro, construido a través de su propio discurso, en "oposición al neoliberalismo", y los caracteriza. En el pasado, las decisiones de política económica, adoptadas siguiendo los consejos del FMI, se tomaban en beneficio de los intereses de los de "afuera" y los "poderosos", y en detrimento de los de "adentro" y "débiles"; ahora, por el contrario, las ajustes son "al revés" tal como -entiende- lo demuestra la oferta de canje que con estas palabras está justificando. El ministro de economía describe este cambio de época en los siguientes términos:

\begin{abstract}
Mientras el país se había convertido en un conejillo de indias, mientras la deuda externa se expandía sin cesar, el prestigio del país era muy alto y Argentina era como una cajita feliz de los buenos negocios", explicó. Y agregó que "el prestigio no se gana satisfaciendo a poderes económicos e ideológicos. Se recupera cuando el país tiene crecimiento y crea permanentemente empleo decente, logra inversiones y no recurre a un nuevo endeudamiento sino más bien, como se hizo hasta ahora, lo reduce -art. 40-
\end{abstract}

Lavagna cierra, de esta manera, la lógica discursiva del gobierno argentino en el canje desenmascarando las contradicciones que, considera, operan en las prácticas de los agentes centrales de la globalización neoliberal. Cuando "la deuda externa se expandía sin cesar" el prestigio del país era muy alto. Ahora, por el contrario, que el "país tiene crecimiento y crea permanentemente empleo decente, logra inversiones y no recurre a un nuevo endeudamiento" dicho prestigio no existe. Por lo tanto, el apoyo de los operadores financieros no se consigue por las señales espontáneas del mercado, tal

enorme cantidad de capitales del sistema financiero local en momentos de recesión. "“" Cómo puede ser? Nosotros argumentamos que los responsables son los bancos que engañaron a sus clientes y (el secretario de finanzas argentino) Nielsen va y pide perdón como si la culpa fuera nuestra", exclamó el Presidente [...] "Hasta la Justicia considera responsables a los bancos y nosotros pedimos perdón" -art. 42-". 
como lo postulan sus promotores, sino, para el ministro, convirtiendo al país en "una cajita feliz de los buenos negocios" y satisfaciendo los "poderes económicos e ideológicos".

El espejo de la narrativa del Ejecutivo nacional devuelve así, la imagen una sociedad polarizada en la cual el poder se encuentra concentrado en un grupo de agentes que definen las reglas de juego de conformidad a sus propios intereses y en virtud de acuerdos más o menos explícitos. Se trata de una imagen que se opone a la difundida por la ortodoxia neoliberal en la que subyace la idea de un mercado de agentes con poderes fragmentados y atomizados que dirigen sus acciones de forma auto-regulada en función de los principios del libre juego de la oferta y la demanda ${ }^{34}$.

\section{IV- Reflexiones finales}

La dilatada participación del FMI en Argentina durante los años 90 activó un extendido debate tendiente a dilucidar las causas que desencadenaron la crisis del 2001. Lo que estaba en cuestionamiento bajo este objetivo inmediato era, en realidad, las bondades del neoliberalismo como modelo de desarrollo económico-social. El canje de la deuda en default se convirtió en este contexto en una caja de resonancia de las distintas visiones en disputa; visiones de las cuales este trabajo analizó, por cuestiones de factibilidad, únicamente aquella del gobierno argentino.

Esta, y tal como se observó, se construyó de principio a fin en torno a la asociación de dos nociones no necesariamente vinculadas entre sí: "neoliberalismo" y "FMI"35. Partiendo de esta asociación, el Ejecutivo nacional instauró una lógica discursiva caracterizada en esencia por la "inversión" de los postulados a través de los cuales esta institución intentó legitimar su actuación en el escenario ex-post 2001; el análisis

\footnotetext{
${ }^{34}$ Las últimas palabras del ministro, relativas a la recuperación del prestigio internacional, cobran en la narrativa del gobierno una significación especial en tanto muestran su voluntad de insertarse en "el mundo" pero de manera diferente a la anteriormente desarrollada. En términos del presidente, en cruce mediático con el director gerente del FMI que pretendía influir sobre el proceso privatizador argentino: "después de todas las cosas que nos pasaron con el Fondo, se lo voy a decir con mesura: somos un país independiente, que sabe administrar y esos consejos no son necesarios. Queremos las inversiones de todo el mundo. Pero ese tipo de tutelajes no lo deseamos -art. 56-".

${ }^{35}$ En este sentido debe advertirse que para los denominados "críticos ortodoxos" esta institución no sólo no comulga con esta doctrina económica social sino que, paradójicamente, se opone a ella desde el momento en que a partir de su "intervención planificada" en los países en crisis impide que el mercado, como mecanismo de asignación de recursos auto-regulado, promueva el crecimiento económico de manera eficiente y prevenga la aparición de prácticas especulativas reñidas con la sana competencia, Kulfas y Schorr (2003). Op. Cit.
} 
efectuado permite mostrar que, en particular, el discurso del gobierno en el canje procuró invertir los siguientes postulados:

a) "La crisis del 2001 se generó por un excesivo gasto público": de conformidad a su narrativa, ésta se desencadenó por el fracaso del proyecto neoliberal. La responsabilidad del FMI en Argentina deviene, consecuentemente, de haber exigido a sus autoridades la implementación de dicho proyecto.

b) "El neoliberalismo es un modelo que promueve el desarrollo económico de los países emergentes": de acuerdo a su relato, éste es un modelo que fomenta el endeudamiento y las prácticas especulativas. La prueba más palpable de dicha afirmación es, en su discurso, el default de la deuda externa que se está negociando.

c) "Los ajustes estructurales constituyen los mecanismos más eficientes para luchar contra las crisis financieras": para su lógica, éstos no fomentan la recuperación económica sino, por el contrario, la previenen. Esto es así, porque restringen la liquidez del Estado, minan el consumo y la inversión. Asimismo, atentan contra el sustento político de los gobernantes al aumentar el desempleo, la pobreza y la desindustrialización.

d) "La economía debe ordenarse en torno a la correcta integración del mercado financiero local al internacional": según su narrativa, dicha integración no supone un "fin en sí mismo". En el caso concreto, debe satisfacerse en primer término la deuda social interna y afrontarse, en segundo término, el pago de la deuda externa.

e) "El neoliberalismo, en la práctica, no es un modelo fundamentado en principios económicos abstractos y beneficiosos para el conjunto de la sociedad": de conformidad a su lógica, éste fomenta los intereses de los países centrales y de los grandes capitales. El FMI no debe coordinar los procesos de canje en la medida en que no constituye una institución equidistante entre ambas partes en tratativas (vgr. deudor y acreedores). Sus políticas, en último término, socializan las pérdidas de los grandes capitales transfiriendo los costos de las crisis a los sectores sociales más afectados por ellas.

Se trata, como puede advertirse, de una lógica argumentativa que desafía presupuestos centrales de la concepción ortodoxa de la sociedad, trayendo de vuelta al Estado y redefiniendo el rol de la Nación en la era de la globalización. Su trascendía deviene de observar que, sería precisamente esta lógica, aquella que en adelante legitimaría las prácticas del gobierno argentino y fijaría los tiempos de su agenda política. 
En este sentido se pronuncia Martínez ${ }^{36}$ al señalar que el kirchnerismo es un movimiento que se auto-construye como un movimiento opuesto en esencia al neoliberalismo.

La estrategia discursiva de confrontación con el FMI desempeñó, en el canje y para sus aspiraciones políticas, las funciones que se enumeran a continuación:

a) Procuró mostrar a la opinión pública la imagen de un Ejecutivo nacional expeditivo y enérgico y, como tal, diferente a la de los presidentes asociados a los acontecimientos de la crisis del 2001. La figura de Kirchner intentó edificarse -desde su propio discurso- en torno a las cualidades de un líder "pragmático", "fuerte" e "intransigente" que, por un lado, lo conectase al imaginario de los líderes peronistas de la década de los 70 y, por otro, lo apuntalase en el centro del campo político en un momento de escasa gobernabilidad. Desde la oposición estas mismas cualidades fueron leídas como síntomas de un oficialismo no abierto al dialogo y con ciertas tendencias "antidemocráticas"37.

b) Buscó convertir al FMI en una suerte de: 1) "chivo expiatorio" de las tensiones que surcaban la sociedad argentina luego de la crisis del 2001 y diluir la responsabilidad por lo acontecido en diferentes agentes sociales; 2) "enemigo externo" al cual el pueblo argentino rápidamente debería vencer. En efecto, se trató de una estrategia discusiva destinada a alinear a sectores del campo político hasta entonces sino enemistados al menos no alineados en defensa de la posición del gobierno en el canje devenida ahora en "causa nacional".

c) Pretendió recrear, especialmente a partir de la promoción de los resultados alcanzados en la negociación, el "mito fundacional" de una nueva patria construida, en su narrativa y como ya se mencionó, en oposición a las políticas neoliberales implementadas en las décadas precedentes.

La distancia existente entre, por un lado, el discurso del gobierno y, por otro, su práctica política efectiva no minó su imagen frente a la opinión pública. En palabras de Novaro:

Lo cierto es que mucha de la retórica radicalizada (del oficialismo) no fue acompañada de decisiones concretas [...]. La tensión entre un discurso confrontativo y decisiones políticas en general muy moderadas, incluso en algunos casos francamente contrapuestas a esas señales discursivas, no representó un

\footnotetext{
${ }^{36}$ Martinez, F. (Comp.). (2011). Op. Cit.

37 Ibidem.
} 
problema para la creación de un consenso ni para el fortalecimiento de la credibilidad del presidente en el electorado. ${ }^{38}$

\section{Referencias}

Ambort, Matilde (2011). "Fundamentos discursivos del programa Familias por la Inclusión Social. Hegemonía discursiva neoliberal: ¿continuidades o rupturas?”. In Martinez, F. (2011). Lecturas del presente: discurso, política y sociedad, Villa María: Ed. Eduvim, p. 51-69.

Krueger, Anne (2002). "Prevención y Solución de Crisis: Lecciones desde Argentina". In Conferencia sobre la "Crisis Argentina", Cambridge, 17 de Julio. Disponible en: http://cdi.mecon.gov.ar/biblio/docelec/nber/books/Arg/krueger.pdf. Consulta: 01 de septiembre 2010.

Kulfas, Matías y Martín Schorr (2003). La Deuda Externa Argentina: Diagnóstico y lineamientos propositivos para su reestructuración. Disponible en: http://www.flacso.org.ar/uploaded_files/Publicaciones/240_AEYT_La.deuda.externa.argen tina.pdf. Consulta: 01 de septiembre 2010.

Lavagna, Roberto (1999). Neoconservadurismo vs Capitalismo Competitivo, Buenos Aires: Ed. Fondo de Cultura Económica, p. 13-45.

Lozano, Claudio (2002). Catástrofe Social en Argentina: la situación a junio de 2002, Buenos Aires, Instituto de Estudios y Formación de la CTA: Ed. de la Universidad Nacional de La Plata.

Manzo, Alejandro G. (2011). "Estado y Derecho en la era de la globalización neoliberal: fundamentos de la ilegitimidad de la deuda externa argentina". In XII Congreso Nacional y II Latinoamericano de Sociología Jurídica, 3, 4 y 5 noviembre, La Pampa, Argentina.

(2012). El canje de la deuda externa 2003-2005: estrategias y discursos del gobierno kirchnerista tenientes a la configuración de un emergente Estado post-neoliberal. Tesis de la Maestría en Sociología del Centro de Estudios Avanzados (CEA) de la UNC, director: Julio Gambina, co-directora: Patricia Scarponetti (inédita).

Manzo, A. G.; González Salva, C. (2012). "La crisis del neoliberalismo en Argentina. Una mirada retrospectiva sobre las causas del default 2001. Buscando razones para entender el quiebre de nuestro país con el FMl". In Passagens: Revista Internacional de Historia Política y Cultura Jurídica, Universidade Federal Fluminense, v. 4, n. 2, mayo-agosto, p. 299-327.

${ }^{38}$ Novaro, M. (2006). Op. Cit., p. 304. 
Martinez, Fabiana (Comp.). (2011). Lecturas del presente: discurso, política y sociedad, Villa María: Eduvim.

Mussa, Michael (2002). Argentina y el Fondo: Del Triunfo a la Tragedia. Disponible en: http://bookstore.piie.com/book-store//343.html. Consulta: 01 de septiembre 2010.

Novaro, Marcos (2006). Historia de la Argentina Contemporánea: de Perón a Kirchner, Buenos Aires: Edhasa.

Rapoport, Mario (2010). Las políticas económicas de la Argentina. Una Breve Historia, Buenos Aires: Booket.

Reynares, Juan M. (2011). "El discurso tecnocrático y las huellas de la hegemonía neoliberal". In Martinez, F. (2011). Lecturas del presente: discurso, política y sociedad, Villa María: Eduvim, p. 29-50.

Stiglitz, Joseph (2002). Argentina, de vuelta el cambio completo: ¿Porqué la nación que siguió las reglas estalló en pedazos. Disponible en: http://www.yorku.ca/robarts/archives/institute/2002/stiglitz_argentina.pdf. Consulta: 01 de septiembre 2010.

Takagi, Shinji y otros (2004). Informe sobre la evaluación del Papel del FMI en Argentina, 1991-2001, Oficina de Evaluación Independiente del FMI. Disponible en: http://www.ieoimf.org/eval/complete/pdf/07292004/espanol.pdf. Consulta: 01 de septiembre 2010.

Vasilachis, Irene (2003). Pobres, pobreza, identidad y representaciones sociales, Barcelona: Gedisa.

Verón, Eliseo (1987). Discurso Político. Lenguaje y Acontecimientos: la palabra adversativa, Buenos Aires: Hachette.

Weisbrot, Mark (2002). Declaraciones ante el Subcomité en Política Monetaria y Comercial Internacional del Comité de Servicios Financieros de la Cámara de Diputados del Congreso de los EEUU, la crisis económica argentina: causas y remedios. Disponible en: http://Financialservices.House.Gov/Media/Pdf/107-52.Pdf. Consulta: 01 de septiembre 2010.

Wodak, Ruth (2003). "El enfoque histórico del discurso". In Wodak, R. y M. Meyer (2003), Métodos de análisis crítico del discurso, Barcelona: Gedisa. 
Anexo:

\begin{tabular}{|c|c|}
\hline Fecha & $\begin{array}{l}\text { Titulares de los artículos del Diario Clarín que transcriben discursos o } \\
\text { fragmentos de discursos de las autoridades argentinas en el canje. }\end{array}$ \\
\hline \multicolumn{2}{|l|}{ Año 2003} \\
\hline 1) $2003 / 06 / 24$ & $\begin{array}{l}\text { http://edant.clarin.com/diario/2003/06/24/um/m-579308.htm } \\
\text { El Gobierno y el Fondo avanzarán en un acuerdo de mediano plazo }\end{array}$ \\
\hline 2) $2003 / 07 / 02$ & $\begin{array}{l}\text { http://edant.clarin.com/diario/2003/07/02/um/m-583325.htm } \\
\text { Nielsen, duro con un sector del Fondo }\end{array}$ \\
\hline 3) $2003 / 07 / 08$ & $\begin{array}{l}\text { http://edant.clarin.com/diario/2003/07/08/e-01501.htm } \\
\text { El Gobierno endurece su postura en la negociación con el Fondo }\end{array}$ \\
\hline 4) $2003 / 07 / 11$ & $\begin{array}{l}\text { http://edant.clarin.com/diario/2003/07/11/e-01001.htm } \\
\text { Se tensó la discusión con el FMl }\end{array}$ \\
\hline 5) $2003 / 07 / 14$ & $\begin{array}{l}\text { http://edant.clarin.com/diario/2003/07/14/um/m-589162.htm } \\
\text { Kirchner vinculó a los organismos internacionales con la "decadencia" argentina }\end{array}$ \\
\hline 6) $2003 / 08 / 28$ & $\begin{array}{l}\text { http://edant.clarin.com/diario/2003/08/28/um/m-613344.htm } \\
\text { Lavagna dice que la negociación cumple el "cronograma previsto" }\end{array}$ \\
\hline 7) $2003 / 09 / 03$ & $\begin{array}{l}\text { http://edant.clarin.com/diario/2003/09/03/e-00501.htm } \\
\text { El Gobierno le pega al FMI, pero muestra voluntad de negociar }\end{array}$ \\
\hline 8) $2003 / 09 / 05$ & $\begin{array}{l}\text { http://edant.clarin.com/diario/2003/09/05/um/m-617480.htm } \\
\text { Kirchner: "El FMI no tiene que hacer lobby para grupos empresarios" }\end{array}$ \\
\hline 9) $2003 / 09 / 06$ & $\begin{array}{l}\text { http://edant.clarin.com/diario/2003/09/06/um/m-618193.htm } \\
\text { Kirchner: "No voy a firmar cualquier cosa con el FMl" }\end{array}$ \\
\hline 10) $2003 / 09 / 07$ & $\begin{array}{l}\text { http://edant.clarin.com/diario/2003/09/07/p-00501.htm } \\
\text { El Presidente criticó al FMl, pero sin llegar a la ruptura }\end{array}$ \\
\hline 11) $2003 / 09 / 08$ & $\begin{array}{l}\text { http://edant.clarin.com/diario/2003/09/08/p-01401.htm } \\
\text { "El FMI comete un error si pide más del 3\% de superávit fiscal" }\end{array}$ \\
\hline 12) $2003 / 09 / 24$ & $\begin{array}{l}\text { http://edant.clarin.com/diario/2003/09/24/p-00504.htm } \\
\text { Las repercusiones fueron previsibles" }\end{array}$ \\
\hline 13) $2003 / 10 / 07$ & $\begin{array}{l}\text { http://edant.clarin.com/diario/2003/10/07/p-00801.htm } \\
\text { Lavagna aconseja "no asustarse" por los juicios de los acreedores }\end{array}$ \\
\hline 14) $2003 / 10 / 13$ & $\begin{array}{l}\text { http://edant.clarin.com/diario/2003/10/13/p-00301.htm } \\
\text { El Gobierno dice que no pueden embargar los bienes del Estado }\end{array}$ \\
\hline 15) $2003 / 10 / 20$ & $\begin{array}{l}\text { http://edant.clarin.com/diario/2003/10/20/p-01001.htm } \\
\text { El Gobierno rechazó críticas de EE.UU. por la relación con Cuba. }\end{array}$ \\
\hline 16) $2003 / 12 / 03$ & $\begin{array}{l}\text { http://edant.clarin.com/diario/2003/12/03/p-01601.htm } \\
\text { Lavagna dice que los bancos "están aprendiendo a prestar" }\end{array}$ \\
\hline 17) $2003 / 12 / 20$ & $\begin{array}{l}\text { http://edant.clarin.com/diario/2003/12/20/p-00301.htm } \\
\text { Kirchner apuntó al FMI, pero a la vez se pagaron US\$ } 268 \text { millones }\end{array}$ \\
\hline 18) $2003 / 12 / 24$ & $\begin{array}{l}\text { http://edant.clarin.com/diario/2003/12/24/p-00601.htm } \\
\text { La misión del FMI se fue sin lograr un acercamiento con el Gobierno }\end{array}$ \\
\hline 19) $2003 / 12 / 25$ & $\begin{array}{l}\text { http://edant.clarin.com/diario/2003/12/25/um/m-681999.htm } \\
\text { El Gobierno dice que no hay "nada que discutir" con el FMI }\end{array}$ \\
\hline Año 2004 & \\
\hline 20) $2004 /$ ene/06 & $\begin{array}{l}\text { http://www.clarin.com/diario/2004/01/06/p-01101.htm } \\
\text { Ahora el Gobierno dice que no habrá pagos adicionales por la deuda }\end{array}$ \\
\hline 21) $2004 /$ ene $/ 13$ & $\begin{array}{l}\text { http://www.clarin.com/diario/2004/01/13/p-00315.htm } \\
\text { Kirchner rechaza el pedido del FMl para reducir la quita del 75\% }\end{array}$ \\
\hline 22) $2004 / \mathrm{feb} / 08$ & $\begin{array}{l}\text { http://www.clarin.com/diario/2004/02/08/p-00302.htm } \\
\text { Una veloz respuesta del Gobierno }\end{array}$ \\
\hline 23) $2004 / \mathrm{feb} / 12$ & $\begin{array}{l}\text { http://www.clarin.com/diario/2004/02/12/p-00501.htm } \\
\text { Kirchner dice que no paga con reservas si el FMI no aprueba antes la revisión }\end{array}$ \\
\hline 24) $2004 / \mathrm{mar} / 06$ & $\begin{array}{l}\text { http://www.clarin.com/diario/2004/03/06/p-00601.htm } \\
\text { Bielsa buscó comprensión entre los embajadores más duros de la UE }\end{array}$ \\
\hline 25) $2004 / \mathrm{mar} / 09$ & $\begin{array}{l}\text { http://www.clarin.com/diario/2004/03/09/p-00601.htm } \\
\text { Kirchner sintetizó la posición del Gobierno: "Ya está todo dicho" }\end{array}$ \\
\hline 26) $2004 / \mathrm{mar} / 10$ & http://www.clarin.com/diario/2004/03/10/um/m-722260.htm \\
\hline
\end{tabular}




\begin{tabular}{|c|c|}
\hline & $\begin{array}{l}\text { Kirchner negó cambios en la oferta a los acreedores: "No existe una } \\
\text { contrapropuesta" }\end{array}$ \\
\hline 27) $2004 / \mathrm{may} / 27$ & $\begin{array}{l}\text { http://www.clarin.com/diario/2004/05/27/elpais/p-00601.htm } \\
\text { Deuda: el Gobierno flexibiliza más la oferta e incluiría los intereses }\end{array}$ \\
\hline 28) 2004/jun/23 & $\begin{array}{l}\text { http://edant.clarin.com/diario/2004/06/23/elpais/p-00601.htm } \\
\text { Lavagna prometió al FMI acelerar la reforma de los bancos públicos }\end{array}$ \\
\hline 29) 2004/jul/23 & $\begin{array}{l}\text { http://edant.clarin.com/diario/2004/07/23/elpais/p-01601.htm } \\
\text { Lavagna habló con Rato: le pidió que no demore la aprobación de metas }\end{array}$ \\
\hline 30) $2004 / j u l / 24$ & $\begin{array}{l}\text { http://edant.clarin.com/diario/2004/07/24/elpais/p-02401.htm } \\
\text { Deuda: Lavagna advierte que el FMI podría interferir en la negociación . }\end{array}$ \\
\hline 31) $2004 / \mathrm{sep} / 01$ & $\begin{array}{l}\text { http://edant.clarin.com/diario/2004/09/01/elpais/p-00301.htm } \\
\text { La reunión entre Kirchner y Rato terminó con reclamos cruzados }\end{array}$ \\
\hline 32) 2004/sep/22 & $\begin{array}{l}\text { http://edant.clarin.com/diario/2004/09/22/elpais/p-00301.htm } \\
\text { Kirchner habló en la ONU y fue duro en las críticas al Fondo }\end{array}$ \\
\hline 33) $2004 / \operatorname{sep} / 23$ & $\begin{array}{l}\text { http://edant.clarin.com/diario/2004/09/23/elpais/p-00301.htm } \\
\text { Kirchner dijo que la oferta a los bonistas es "única y definitiva" }\end{array}$ \\
\hline 34) $2004 / \mathrm{sep} / 29$ & $\begin{array}{l}\text { http://edant.clarin.com/diario/2004/09/29/elpais/p-00301.htm } \\
\text { Lavagna habló de repago de deuda y subieron más los bonos }\end{array}$ \\
\hline 35) $2004 /$ nov/21 & $\begin{array}{l}\text { http://edant.clarin.com/diario/2004/11/21/elpais/p-00301.htm } \\
\text { Lavagna: los que no entren al canje de deuda no cobrarán }\end{array}$ \\
\hline 36) $2004 / \mathrm{dic} / 01$ & $\begin{array}{l}\text { http://edant.clarin.com/diario/2004/12/01/elpais/p-00401.htm } \\
\text { Kirchner insiste: la oferta a los bonistas no tendrá cambios }\end{array}$ \\
\hline Año 2005 & \\
\hline 37) $2005 / 01 / 13$ & $\begin{array}{l}\text { http://edant.clarin.com/diario/2005/01/13/um/m-903681.htm } \\
\text { Kirchner, a un día del inicio del canje: "La propuesta que hicimos no se cambia" }\end{array}$ \\
\hline 38) 2005/01/13 & $\begin{array}{l}\text { http://edant.clarin.com/diario/2005/01/13/elpais/p-00301.htm } \\
\text { Lavagna lanzó el canje y reiteró que no habrá una nueva oferta }\end{array}$ \\
\hline 39) $2005 / 01 / 14$ & $\begin{array}{l}\text { http://edant.clarin.com/diario/2005/01/14/um/m-904110.htm } \\
\text { Nielsen reiteró que es "la mejor oferta sustentable" }\end{array}$ \\
\hline 40) $2005 / 01 / 12$ & $\begin{array}{l}\text { http://edant.clarin.com/diario/2005/01/12/um/m-902810.htm } \\
\text { Lavagna presentó el canje y asegura que se conforma con el 50\% de aceptación }\end{array}$ \\
\hline 41) $2005 / 01 / 16$ & $\begin{array}{l}\text { http://edant.clarin.com/diario/2005/01/16/um/m-905270.htm } \\
\text { Cristina Kirchner volvió a cuestionar a los organismos de crédito }\end{array}$ \\
\hline 42) $2005 / 01 / 19$ & $\begin{array}{l}\text { http://edant.clarin.com/diario/2005/01/21/elpais/p-01101.htm } \\
\text { Kirchner se enojó con Nielsen porque pidió perdón en Italia }\end{array}$ \\
\hline 43) 2005/01/25 & $\begin{array}{l}\text { http://edant.clarin.com/diario/2005/01/25/um/m-910553.htm } \\
\text { Kirchner: "No somos el país del default, ni el del corralito, ni el de la devaluación" }\end{array}$ \\
\hline 44) 2005/01/27 & $\begin{array}{l}\text { http://edant.clarin.com/diario/2005/01/27/um/m-911732.htm } \\
\text { Lavagna denunció maniobras destinadas a desalentar el canje }\end{array}$ \\
\hline 45) $2005 / 01 / 27$ & $\begin{array}{l}\text { http://edant.clarin.com/diario/2005/01/27/um/m-911747.htm } \\
\text { Kirchner: "La oferta de canje de la deuda no se cambia" }\end{array}$ \\
\hline 46) 2005/02/04 & $\begin{array}{l}\text { http://edant.clarin.com/diario/2005/02/04/um/m-916196.htm } \\
\text { Duro mensaje de Kirchner a los bonistas }\end{array}$ \\
\hline 47) $2005 / 02 / 19$ & $\begin{array}{l}\text { http://edant.clarin.com/diario/2005/02/19/um/m-924982.htm } \\
\text { Canje de la deuda: ratifican que no habrá cambios en la oferta }\end{array}$ \\
\hline 48) 2005/02/25 & $\begin{array}{l}\text { http://edant.clarin.com/diario/2005/02/25/um/m-928447.htm } \\
\text { Kirchner pronosticó "un buen resultado" para el canje }\end{array}$ \\
\hline 49) $2005 / 02 / 28$ & $\begin{array}{l}\text { http://edant.clarin.com/diario/2005/02/28/um/m-930184.htm } \\
\text { Según Kirchner, el país llegó a "un punto de inflexión" con el canje }\end{array}$ \\
\hline 50) 2005/03/01 & $\begin{array}{l}\text { http://edant.clarin.com/diario/2005/03/01/um/m-930690.htm } \\
\text { Kirchner anunció el final del default con una "drástica reducción" de la deuda }\end{array}$ \\
\hline 51) $2005 / 03 / 02$ & $\begin{array}{l}\text { http://edant.clarin.com/diario/2005/03/02/um/m-931487.htm } \\
\text { Kirchner y Lavagna anuncian mañana a la tarde los resultados del canje }\end{array}$ \\
\hline 52) $2005 / 03 / 02$ & $\begin{array}{l}\text { http://edant.clarin.com/diario//um/m-931579.htm } \\
\text { Alberto Fernández adelantó que fue "lo suficientemente amplia" la adhesión al } \\
\text { canje }\end{array}$ \\
\hline 53) 2005/03/03 & $\begin{array}{l}\text { http://edant.clarin.com/diario/2005/03/03/um/m-932075.htm } \\
\text { "Se superó uno de los mayores obstáculos para la economía" }\end{array}$ \\
\hline
\end{tabular}




\begin{tabular}{|l|l|}
\hline 54) 2005/03/04 & $\begin{array}{l}\text { http://edant.clarin.com/diario/2005/03/04/um/m-932822.htm } \\
\text { Nielsen criticó la "burocracia" del FMl y volvió a descartar que se reabra el canje }\end{array}$ \\
\hline 55) 2005/03/05 & $\begin{array}{l}\text { http://edant.clarin.com/diario/2005/03/05/um/m-933342.htm } \\
\text { Kirchner acusó al FMI de haber dejado sólo al país en la negociación del canje }\end{array}$ \\
\hline 56) 2005/03/06 & $\begin{array}{l}\text { http://edant.clarin.com/diario/2005/03/06/elpais/p-00301.htm } \\
\text { Kirchner aseguró que el Fondo fracasó y le pidió una autocrítica }\end{array}$ \\
\hline 57) 2005/03/06 & $\begin{array}{l}\text { http://edant.clarin.com/diario/2005/03/06/elpais/p-00815.htm } \\
\text { "No hay nada que celebrar, ahora hay que hacer un esfuerzo enorme" }\end{array}$ \\
\hline 58) 2005/03/16 & $\begin{array}{l}\text { http://edant.clarin.com/diario/2005/03/16/um/m-939730.htm } \\
\text { Kirchner le respondió al jefe del Fondo: "Ojalá ahora ayude de verdad" }\end{array}$ \\
\hline 59) 2005/03/17 & $\begin{array}{l}\text { http://edant.clarin.com/diario/2005/03/17/elpais/p-00301.htm } \\
\text { Kirchner, otra vez duro con el FMI: "No necesitamos sus consejos" }\end{array}$ \\
\hline
\end{tabular}

Recebido para publicação em dezembro de 2012.

Aprovado para publicação em fevereiro de 2013. 